\title{
Influence of fluorinated surfactants on the efficacy of some post- emergence sulfonylurea herbicides
}

\author{
Fabio Stagnari,* Marco Chiarini and Michele Pisante \\ Department of Food Science, University of Teramo, Via Carlo R. Lerici, 1, I-64023 Mosciano Stazione, TE, Italy
}

(Received September 1, 2006; Accepted November 7, 2006)

\begin{abstract}
Fluorinated non-ionic surfactants were assessed as adjuvants for tribenuron-methyl, triflusulfuron-methyl and foramsulfuron. The compared adjuvants included hydroxy-terminated fluorinated polyether (PF-151N), polyoxyethylene-alpha-fluoro-omega-(2-hydroxyethyl)poly(difluoromethylene) (Zonyl FSN-100), and polyoxyethylene(23) lauryl ether (Brij 35). Greenhouse experiments were performed to evaluate these surfactants both for their efficacy in controlling weeds and selectivity to crops. Tribenuron-methyl and triflusulfuron-methyl absorption into catchweed and giant foxtail leaves due to surfactant addition was also estimated. Zonyl FSN-100 and Brij 35 allowed a reduction in the application rate of triflusulfuron-methyl to nearly $1 / 2$ of the labelled rate to control redroot pigweed. The foramsulfuron rate was reduced by more than $50 \%$ to control barnyardgrass thanks to the addition of Zonyl FSN-100 and it controlled giant foxtail only applied at the maximum labelled rate and mixed with Zonyl FSN-100. Tribenuron-methyl activity against poppy was only slightly enhanced by the use of adjuvants. Tribenuron-methyl efficacy was clearly enhanced by the use of adjuvants to control catchweed; however, the required dose was not lower than the labelled one. The addition of adjuvants induced slight phytotoxicity in the crops. Brij 35 caused the greatest absorption of triflusulfuron-methyl into giant foxtail leaves and of tribenuron-methyl into catchweed leaves. (C) Pesticide Science Society of Japan
\end{abstract}

Keywords: fluorinated surfactants, adjuvants, foramsulfuron, tribenuron-methyl, triflusulfuron-methyl, herbicide activity.

\section{Introduction}

There is increasing interest in the influence of formulation on the biological activity of pesticides. In particular, for postemergence herbicides, the main focus is on the adjuvant type which can greatly enhance the performance of active ingredients. Since post-emergence herbicide effectiveness is greatly influenced by plant factors such as age, size and growing conditions encountered before application, herbicide performance can vary. In order to minimize performance variations and potential weed control failures, an adjuvant may be added to the spray solution. ${ }^{1-5)}$ Furthermore, the use of adjuvant in the mixture is key to achieving the important objective of reducing post-emergence herbicide application rates to the lowest effective level. Appropriate selection should be made based on several factors such as the differential sensitivity of the targeted weeds and the different potency of the herbicides being

\footnotetext{
* To whom correspondence should be addressed.

E-mail: fstagnari@unite.it

Published online December 29, 2006

(C) Pesticide Science Society of Japan
}

considered. ${ }^{6)}$ Among the broad group of adjuvants, the most suitable for this purpose are activator adjuvants, compounds that, when added to the spray tank, enhance herbicide activity. ${ }^{7)}$ Surfactants are the most widely used and probably the most important among all activator adjuvants. ${ }^{8)}$ They act by facilitating or enhancing the emulsifying, dispersing, spreading, sticking and wetting properties of the herbicide tank mix. Surfactants can also directly influence the absorption of herbicides by changing the viscosity and crystalline structure of waxes on leaf and stem surfaces. ${ }^{9-11)}$ Surfactants can be non-ionic, cationic, anionic or amphoteric, but the most commonly recommended and used are non-ionic; among them, polyethoxylated fatty alcohols and organo-silicone surfactants provide a very significant reduction in surface tension and greatly improve herbicide absorption. ${ }^{12,13)}$

Sulfonylurea herbicides are easier to use and have brought significant improvements in weed control for main crops: a large application window, excellent crop safety, tank mix compatibilities and low mammalian toxicity have all helped their success. ${ }^{14)}$ It has been proved that the performance of some sulfonylureas is increased by the addition of tank-mix 
oils. ${ }^{15-17)}$ Moreover, non-ionic surfactants have been effective in improving the activity of primisulfuron, rimsulfuron, and thifensulfuron. ${ }^{18-21)}$ It is widely accepted that the adjuvant effect is species specific: different adjuvants interact differently with different herbicides on different species. ${ }^{22)}$ In this regard, herbicide dose-response curves must be determined, under various adjuvant conditions, for the weeds that are most difficult to control. ${ }^{23)}$ Since polyethoxylated fatty alcohol surfactants enhance the penetration of polar and non-polar pesticides, they are often added to the mixture to enhance sulfonylurea activity. This could be explained by evidence that nonionic surfactants may penetrate the cuticle relatively rapidly and in large amounts, ${ }^{24)}$ causing swelling and hydration of the cuticular membrane and affecting the plasticizing or solubilizing of waxes. ${ }^{25)}$ It has been proven, both empirically and by means of modelling, that the most effective polyethoxylated fatty alcohol surfactants for sulfonylurea range from a hydrophobe with 17 carbons and a hydrophilic group with 20 to 30 ethylene oxide groups (EOs) to a hydrophobe with 24 carbons and $13 \mathrm{EOs}^{21)}$ If hydrogen in the hydrophobic hydrocarbon part of the surfactant is replaced by fluorine, greater hydrophobicity of the fluorocarbon chain enhances the amphiphilic character of the surfactant and increases surface activity. This is reflected by surface tension below $20 \mathrm{dyn} / \mathrm{cm}$ and lower CMC (critical micellar concentration) values and has beneficial effects on wetting, detergency and solubilization since they depend on the CMC of the micellar solution. ${ }^{26)}$ Fluorination reduces $\mathrm{CMC}$ values about four times per $-\mathrm{CF}_{2}-$ group. ${ }^{27)}$ They are powerful wetting and spreading agents, they increase liquid penetration and, when compared to hydrocarbon surfactants, they are better wetting agents for leaves. $^{27)}$

Those characteristics could be very interesting for enhancing herbicide activity and, as far as we understand, there are no data available in the literature on the use of fluorosurfactants as agrochemical adjuvants. We therefore considered two fluorosurfactants, Zonyl FSN-100 and PolyFox 151N (PF$151 \mathrm{~N})$, and, as a comparison, Brij 35, which is the analogue hydrocarbon counterpart of Zonyl FSN-100. Zonyl FSN-100 and Brij 35 are polyethoxylated alcohols with hydrophobe and hydrophilic groups in the range reported to be the most effective. PF-151N, a non-ionic fluorosurfactant, has been selected because it is environmentally preferred, compared to Zonyl telomer-based and other conventional fluorosurfactants.

The objectives of this research were to: (1) evaluate the effectiveness of the abovementioned fluorinated surfactants in enhancing foliar activity of tribenuron-methyl, triflusulfuronmethyl and foramsulfuron to some weed species which are difficult to control, and (2) determine if the addition of surfactants influences herbicide phytotoxicity to crops.

\section{Materials and Methods}

Seeds of Amaranthus retroflexus (redroot pigweed), Chenopodium album (common lambsquarters), Echinochloa crus-galli (barnyardgrass), Galium aparine (catchweed), $\mathrm{Pa}$ paver rhoeas (poppy), and Setaria faberi (giant foxtail) were planted in $15 \mathrm{~cm}$-diam plastic pots containing commercial potting mix. Seeds of wheat, corn and sugar beet were planted in $30 \mathrm{~cm}$-diam plastic pots containing commercial potting mix. Plants were thinned to three uniform plants per pot one week after emergence and were watered and fertilized as needed for healthy and rapid growth. Metal halide lamps with $160 \mu \mathrm{E} \mathrm{m}^{-2} \mathrm{~s}^{-1}$ photosynthetically active radiation supplemented natural intensity during a 16-hr photoperiod when light intensity was below $500 \mu \mathrm{E} \mathrm{m}^{-2} \mathrm{~s}^{-1}$. The greenhouse was maintained at $20^{\circ} \mathrm{C}$ at night and $25^{\circ} \mathrm{C}$ during the $16-\mathrm{hr}$ day. Relative humidity ranged from $50 \%$ to $90 \%$. Herbicide spraying was performed for pots containing three uniform plants.

The tribenuron-methyl formulation was $75 \%$ active waterdispersible granules (Granstar), triflusulfuron-methyl was $50 \%$ active water-dispersible granules (Safari), and foramsulfuron was $35 \%$ active water-dispersible granules (Option). All weed species were sprayed using a hand nozzle sprayer calibrated to deliver 300 1/ha through an ALBUZ APG 110 -yellow flat fan nozzle at an operating pressure of $300 \mathrm{kPa}$. The height of the giant foxtail at application was $5-7 \mathrm{~cm}$, barnyardgrass 5-6 cm, common lambsquarters $4-5 \mathrm{~cm}$, catchweed $10 \mathrm{~cm}$, poppy $3-4 \mathrm{~cm}$ and redroot pigweed $4-5 \mathrm{~cm}$. Tribenuron-methyl doses were 1.5, 3.0, 6.0, 11.3 and $15.0 \mathrm{~g}$ a.i./ha, triflusulfuron-methyl doses were $2.5,5.0,10,20$ and $30 \mathrm{~g}$ a.i./ha, and foramsulfuron doses were 3, 6, 12, 24, 40 and $50 \mathrm{~g}$ a.i./ha. Each herbicide dose was applied alone and with three different adjuvant systems, which included two fluorinated surfactants polyoxyethylene-alpha-fluoro-omega-(2-hydroxyethyl)poly(difluoromethylene) (Zonyl FSN-100; DuPont product) and hydroxy-terminated fluorinated polyether (PF-151N; OMNOVA Solutions Inc.), and one hydrocarbon surfactant as a comparison, polyoxyethylene(23) lauryl ether (Brij 35; ICI Americas).

Zonyl FSN-100 was applied at $0.01 \%$ of the spray volume ( $0.11 \mathrm{mM}$ corresponding to 10 times the CMC), Brij 35 was applied at $0.04 \%$ of the spray volume $(0.33 \mathrm{mM}$ corresponding to 3.3 times the $\mathrm{CMC}$ ) and $\mathrm{PF}-151 \mathrm{~N}$ dose was $0.1 \%$ of the spray volume $(0.44 \mathrm{mM}$ corresponding to a surface tension of $24 \mathrm{dyn} / \mathrm{cm}$ in $\mathrm{pH} 7$ buffered water). Each weed and crop species was managed as an independent greenhouse trial, designed as a randomized complete block with three replications. Each trial was repeated four times. Weeds were harvested and weighed about 14 days after treatment (DAT) with fresh weight reduction converted to percent control.

Each active ingredient-adjuvant combination was also tested in terms of injury to the crops for which they are normally used to control weeds: tribenuron-methyl was applied on wheat at the 4-leaf stage, triflusulfuron-methyl was applied on sugar beet at the 4-leaf stage, and foramsulfuron was applied on corn at the 2-leaf stage. The three herbicides were applied at the labelled dose, alone and with the three above- 
mentioned adjuvant systems. Crop response was evaluated 14 DAT visually, based on a scale of $0-100 \%$ where 0 indicated no effect and $100 \%$ complete plant death, respectively.

Tribenuron-methyl and triflusulfuron-methyl absorption into catchweed $10 \mathrm{~cm}$ high plants and into giant foxtail at the 3-leaf stage, due to surfactant addition, was also estimated by measuring the difference between the amount of herbicide applied to the leaves and that recovered after $20 \mathrm{~min}$. The procedure consisted of preparing a $150 \mu \mathrm{l}$ of buffered solution $(0.1 \mathrm{M}$ borate $\mathrm{pH} 9.0)$ of $5 \mathrm{mg} / \mathrm{ml}$ herbicide with or without surfactant (surfactant concentrations were $0.01 \%, 0.04 \%$ or $0.1 \%$ of water volume for Zonyl FSN-100, Brij 35 or PF$151 \mathrm{~N}$, respectively). Solution was buffered to increase sulfonylurea solubility. ${ }^{28)}$

The solutions were applied on plant leaves and left for $20 \mathrm{~min}$; subsequently, the leaves were rinsed with $10 \mathrm{ml}$ buffer solution (0.1 M borate $\mathrm{pH} 9.0$ ) and read on a Lambda Bio 20 UV/Vis spectrometer (Perkin Elmer) at $255 \mathrm{~nm}$ and $234 \mathrm{~nm}$ for tribenuron-methyl and triflusulfuron-methyl, respectively, with the blank being a solution of identical composition without herbicide (three replications). The method was validated for linearity, accuracy and repeatability around the concentration of $5 \times 10^{-5} \mathrm{M}$ by a $0.1 \mathrm{M}$ borate buffer solution ( $\mathrm{pH} 9.0$ ) with the two herbicides, both with and without surfactants; the concentrations for Zonyl FSN-100, Brij 35 and PF-151N were $0.001 \%, 0.004 \%$ and $0.01 \%$ of water volume, respectively. For linearity, a calibration curve with six concentration levels in the range from 20 to $200 \%$ of the nominal concentration was constructed. The relationship between response and concentration was found to be linear in the investigated concentration interval with a correlation coefficient $\left(\mathrm{r}^{2}\right)$ of 0.998 . The accuracy of the method was assessed over the same concentration range that was investigated in the linearity study (20-200\%) by making three independent determinations at each concentration level. In order to estimate repeatability, five consecutive independent measurements of the same test sample with an identical concentration were performed.

The spreading capacity of the tested surfactants was estimated by putting $5 \mu \mathrm{l}$ drops of aqueous solution of each surfactant (surfactant concentration of $0.01 \%, 0.04 \%$ and $0.1 \%$ of water volume for Zonyl FSN-100, Brij 35 and PF-151N, respectively) and 4-methylumbelliferone, added as a fluorescent compound, onto a hydrophobic film under UV light. Twenty minutes after deposition, pictures were taken and the wetted areas compared. The experiment was repeated 5 times.

Statistical analysis. Percentage of weed control was regressed to fit logarithmic dose-response curves that conformed to Eq. (1) ${ }^{29)}$

$$
Y=100 /\{1+\exp \{b[\ln (E D 50 i)-\ln (x)]\}\}
$$

where $Y$ is the percentage efficacy of the herbicide, $x$ is the dose, $b$ is the slope of the curve around its inflection point, $E D 50$ is the dose required to give $50 \%$ efficacy and $i$ is the adjuvant, which was included as a categorical variable in the model.

For each "weed-herbicide-adjuvant" combination, the selected model was used to derive the dose required to give $90 \%$ weed control, assumed to be the minimum dose requirement for satisfactory efficacy. ${ }^{30}$ )

The herbicide dose reduction allowed by the use of adjuvants may be related to the dose required when herbicides are used alone by the ratio " $1-$ ED $90_{\text {herbicide+adjuvant }}$ ' ED90 herbicide alone".

Statistical analysis was performed using the macro programme BIOASSAY97. ${ }^{31)}$

Data regarding crop tolerance and active ingredient absorption into plant leaves were subjected to analysis of variance across experiments and treatment means, and were declared significant at the $5 \%$ level of probability according to Least Significant Difference.

\section{Results and Discussion}

Dose-response curves did not show any lack of fit to observed data; examples are given in Fig. 1. This could be due to the relatively low number of doses which decrease the significance of the tests for lack-of-fit. The number of doses applied in this study (five to six doses) could be an acceptable compromise between a good description of the dose-response curve and the acceptance of tests for lack-of-fit, as previously reported in other experiments. ${ }^{31)}$ In some cases, the selected dose range did not encompass the whole response range of weed species and some were never perfectly controlled, regardless of the application rate and adjuvant.

ED90 levels for triflusulfuron-methyl are reported in Table 1. The ranking of weed species in terms of sensitivity to triflusulfuron-methyl (without adjuvants) was: redroot pigweed $>$ giant foxtail (see ED90s in Table 1); redroot pigweed could be well controlled at the approximate commercial rate (20 g a.i. ha ${ }^{-1}$ ) without adjuvants. Giant foxtail was much less sensitive and could not be controlled regardless of the application rate.

Adjuvants significantly enhanced triflusulfuron-methyl activity, allowing an apparent dose reduction, reaching values in some cases higher than $50 \%$ with respect to herbicide applied alone (Table 1). In more detail, it can be observed that, with respect to giant foxtail, which is not a target weed of this active ingredient, when Zonyl FSN-100 and Brij 35 were added to the mixture, control of this weed was possible, although with a herbicide dose higher than the labelled rate. With the addition of Zonyl FSN-100 and Brij 35 to the mixture, redroot pigweed could be controlled with potential dose reduction for an ED90 of 41 and 45\%, respectively. In other words, in the presence of Zonyl FSN-100 and/or Brij 35, the same weed control efficacy against redroot pigweed could be achieved with nearly half the dose compared to triflusulfuron-methyl alone. In this case, the best performing fluorinated surfactants did not give any advantage, in terms of efficiency, compared to the hydrocarbon surfactant. In some cases it was not possi- 
A

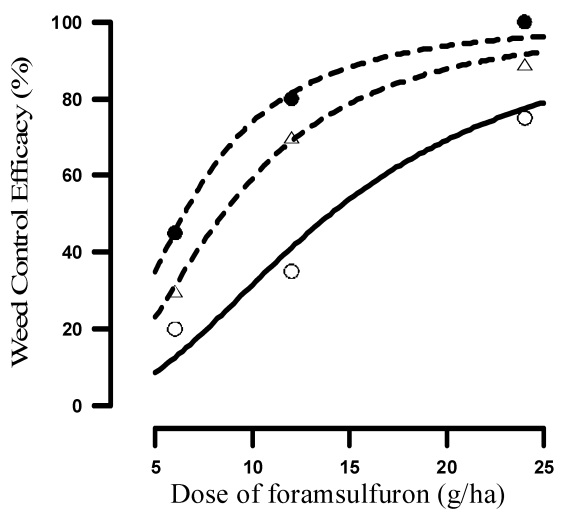

B

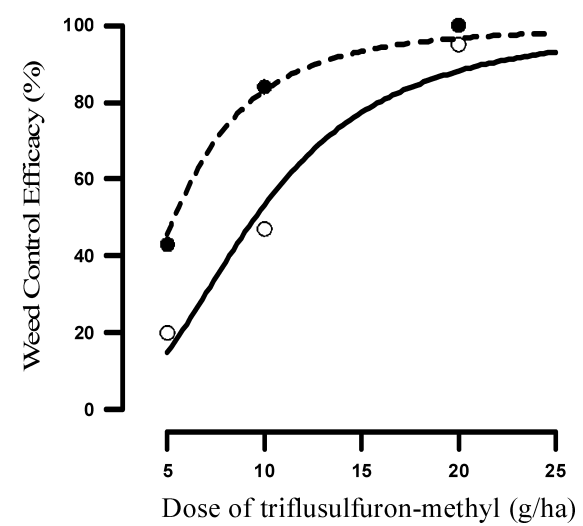

Fig. 1. Example of dose-response curve. Symbols show observed data, lines show fitted curves. A: Significant differences were found between foramsulfuron+Zonyl FSN-100, foramsulfuron+plus Brij 35 and foramsulfuron without adjuvant in the control of barnyardgrass. B: Significant differences were found between triflusulfuronmethyl plus Zonyl FSN-100 and triflusulfuron-methyl without adjuvant in the control of redroot pigweed. White circle and solid line: herbicide alone; black circle and dashed line: herbicide+Zonyl FSN100; triangle and dashed line: herbicide + Brij 35 .

ble to detect significant differences among the mixture herbicide + adjuvants and herbicide applied alone (i.e. PF-151N in redroot pigweed control).

Crop injury was registered at 14 DAT. Typical injury symptoms shown by sugar beet plants, associated with triflusulfuron-methyl application, were leaves that became bright yellow with first yellowing on young leaves (chlorosis); injury was higher when Brij 35 was used as the adjuvant (Table 4) with respect to both fluorinated surfactants, less than $10 \%$ of damage.

The ED90 levels for foramsulfuron are reported in Table 2. Averaged across all treatments, barnyardgrass was the most susceptible species to foramsulfuron, of those examined in this study (Table 2). Considering herbicides alone, only barnyardgrass could be controlled at a rate not higher than the commercial rate. On the other hand, common lambsquarters was not controlled regardless of both the application rate and
Table 1. Regression parameters for the relationship between the dose of triflusulfuron-methyl (alone and with various fluorinate adjuvants) and its efficacy against some weeds

\begin{tabular}{lccc}
\hline $\begin{array}{l}\text { Weed species } \\
\text { Adjuvant }\end{array}$ & $b$ & ED 90 (g/ha) & $\mathrm{R}^{a)}$ \\
\hline $\begin{array}{l}\text { Setaria faberi } \\
\text { No adjuvant }\end{array}$ & $0.97(0.12)$ & $429.1(179.6)$ & \\
Zonyl FSN-100 & $1.62(0.15)$ & $47.2(6.4)$ & 0.89 \\
PF-151N & $1.07(0.13)$ & $263.5(92.0)$ & 0.39 \\
Brij 35 & $1.61(0.15)$ & $49.8(6.98)$ & 0.88 \\
\hline $\begin{array}{l}\text { Amaranthus retroflexus } \\
\text { No adjuvant }\end{array}$ & $2.70(0.45)$ & $21.5(3.2)$ & \\
Zonyl FSN-100 & $2.55(0.21)$ & $12.7(1.03)$ & 0.41 \\
PF-151N & $3.08(0.58)$ & $19.5(2.9)$ & 0.09 \\
Brij 35 & $2.76(0.39)$ & $11.9(1.51)$ & 0.45 \\
\hline a) Standard errors are in parentheses (ED90 was assumed as the \\
minimum dose for satisfactory efficacy). ${ }^{b}$ Relative dose reduc- \\
tion in comparison to thifensulfuron-methyl without adjuvants.
\end{tabular}

Table 2. Regression parameters for the relationship between the dose of foramsulfuron (alone and with various fluorinate adjuvants) and its efficacy against some weeds

\begin{tabular}{lccc}
\hline $\begin{array}{l}\text { Weed species } \\
\text { Adjuvant }\end{array}$ & $b$ & ED90 (g/ha) & $\mathrm{R}^{a}$ \\
\hline $\begin{array}{l}\text { Setaria faberi } \\
\text { No adjuvant }\end{array}$ & $1.97(0.31)$ & $72.2(13.0)$ & \\
Zonyl FSN-100 & $1.66(0.22)$ & $36.2(6.9)$ & 0.50 \\
PF-151N & $1.78(0.23)$ & $68.2(11.3)$ & 0.06 \\
Brij 35 & $1.66(0.24)$ & $41.1(4.9)$ & 0.43 \\
\hline Echinocloa crus-galli & & & \\
No adjuvant & $2.28(0.40)$ & $36.6(6.76)$ & \\
Zonyl FSN-100 & $2.40(0.15)$ & $16.2(1.02)$ & 0.56 \\
PF-151N & $2.19(0.26)$ & $32.7(4.35)$ & 0.11 \\
Brij 35 & $2.29(0.13)$ & $22.1(1.32)$ & 0.40 \\
\hline Chenopodium album & & & \\
No adjuvant & $1.91(0.19)$ & $160.6(23.9)$ & \\
Zonyl FSN-100 & $1.66(0.07)$ & $87.9(5.36)$ & 0.45 \\
PF-151N & $1.68(0.07)$ & $147.0(10.4)$ & 0.08 \\
Brij 35 & $1.68(0.04)$ & $79.5(2.5)$ & 0.50 \\
\hline
\end{tabular}

a) Standard errors are in parentheses (ED90 was assumed as the minimum dose for satisfactory efficacy). ${ }^{b)}$ Relative dose reduction in comparison to foramsulfuron without adjuvants. 
adjuvants, confirming that foramsulfuron is primarily a grass herbicide.

Even though barnyardgrass was the most susceptible species, adjuvant selection significantly affected its control. Zonyl FSN-100 was the most effective adjuvant; it determined a $56 \%$ reduction in the amount of foramsulfuron needed for ED90 compared with no adjuvant application. In this case, the significantly higher efficacy of fluorinated Zonyl FSN-100 should be stressed with respect to hydrocarbon surfactant; that particular behaviour is probably due to barnyardgrass leaf morphology and wax composition and structure. Also, in the case of giant foxtail, Zonyl FSN-100 increased the efficacy of the herbicide mixture allowing satisfactory control within the labelled rate, although not differing significantly to Brij 35. Compared to the herbicide applied alone, the addition of Zonyl FSN-100 allowed a 50\% reduction in the foramsulfuron application dose. This confirmed that the addition of Zonyl FSN-100 to foramsulfuron is the best adjuvant choice for controlling these two grass weeds. Increasing foramsulfuron control of grass species, like giant foxtail and barnyardgrass, by the addition of methylated canola oil to the herbicide mixture has already been reported. ${ }^{33)}$ There was no advantage in adding PF- $151 \mathrm{~N}$ for the purpose of controlling both barnyardgrass and giant foxtail.

Injury to corn was also evaluated, ranging between $2.0 \%$ and $8.7 \%$ from foramsulfuron application 14 DAT (Table 4). Typical injury symptoms associated with foramsulfuron were chlorosis of the upper portion of the plant and shortened leaf internodes that resulted in reduced plant height and they were more evident when Zonyl FSN-100 was used as the adjuvant (highest damage).

The ED90 levels for tribenuron-methyl are reported in Table 3.

The ranking of weed species in terms of sensitivity to tribenuron-methyl (without adjuvants) was: poppy $>$ catchweed (see ED90s in Table 3); poppy could be well controlled at the commercial rate $\left(11.3 \mathrm{ga}\right.$.i. $\left.\mathrm{ha}^{-1}\right)$ without adjuvants while catchweed proved to be less sensitive. Again, adjuvant selection was important for this sulfonylurea, as already stated by Zollinger who found in his study that the most active adjuvants for tribenuron-methyl were methylated seed oil, crop oil concentrate and organosilicone. ${ }^{34)}$ In the control of catchweed, adjuvants significantly enhanced tribenuron-methyl activity, Zonyl FSN-100 being the best performing adjuvant although not significantly different from the hydrocarbon surfactant (Brij 35). It allowed an apparent dose reduction of 95\%, despite the fact that tribenuron-methyl is not particularly effective in controlling this weed, lowering the ED90 to $25.4 \mathrm{~g}$ a.i. $\mathrm{ha}^{-1}$, although still higher than the labelled rate. Brij 35 also allowed a significant ED90 reduction to control catchweed. In the case of poppy, significant differences did not emerge between the sprayed adjuvants. Their addition allowed only a slight reduction in the application dose of tribenuron-methyl. The highest crop injury was recorded when tribenuron-methyl
Table 3. Regression parameters for the relationship between the dose of tribenuron-methyl (alone and with various fluorinate adjuvants) and its efficacy against some weeds

\begin{tabular}{lccc}
\hline $\begin{array}{l}\text { Weed species } \\
\text { Adjuvant }\end{array}$ & $b$ & $\mathrm{ED} 90(\mathrm{~g} / \mathrm{ha})$ & $\left.\mathrm{R}^{a}\right)$ \\
\hline $\begin{array}{l}\text { Galium aparinae } \\
\text { No adjuvant }\end{array}$ & $0.96(0.06)$ & $488.1(126.7)$ & \\
Zonyl FSN-100 & $1.65(0.06)$ & $25.4(1.38)$ & 0.95 \\
PF-151N & $1.24(0.08)$ & $87.3(13.8)$ & 0.82 \\
Brij 35 & $1.48(0.07)$ & $32.7(2.76)$ & 0.93 \\
\hline $\begin{array}{l}\text { Papaver rhoeas } \\
\text { No adjuvant }\end{array}$ & $3.05(0.56)$ & $11.0(1.6)$ & \\
Zonyl FSN-100 & $3.12(0.37)$ & $9.5(0.87)$ & 0.14 \\
PF-151N & $3.02(0.37)$ & $10.2(0.99)$ & 0.07 \\
Brij 35 & $2.74(0.27)$ & $8.8(0.28)$ & 0.20 \\
\hline a) Standard errors are in parentheses (ED90 was assumed as the \\
minimum dose for satisfactory efficacy). ${ }^{b}$ Relative dose reduc- \\
tion in comparison to tribenuron-methyl without adjuvants.
\end{tabular}

was mixed with the hydrocarbon surfactant Brij 35 (Table 4), the main symptom being chlorosis on the younger leaves, but always with values lower than $10 \%$, while both fluorinated surfactants caused significantly fewer injury symptoms to the crop.

Foliar absorption into giant foxtail leaves of triflusulfuronmethyl applied alone was 19.3\%, 20 min after treatment (Fig. 2 ); when an adjuvant was added to the mixture, foliar absorption was significantly increased. These results demonstrate that minimal absorption occurs when the active ingredient is applied to giant foxtail without adjuvants. The greatest level of foliar absorption was observed when Brij 35 was added to the mixture (66\% of foliar absorption, $20 \mathrm{~min}$ after treatment). Zonyl FSN-100 and PF-151N also allowed high active ingredient absorption, and no significant differences were observed between the two adjuvants. In addition, absorption of tribenuron-methyl was generally affected by adjuvants added to treatment mixtures (Fig. 3). Without adjuvants, absorption into treated catchweed leaves was $27.8 \%$. Addition of Zonyl FSN-100 and Brij 35 increased absorption to over 60\%. These results indicated that the tested adjuvants improved herbicide weed control and allowed a higher amount of active ingredients to be carried into the plants. This could partly be explained by taking into account that the studied adjuvants increase adhesion to the target leaves surface and spread over it to cover a large area of the leaves. Comparing data regarding herbicide absorption, as influenced by surfactants, with efficacy on weed control, the absorption level is not always consistent with the efficacy. That is in part apparent because the differences are not always statistically significant; further- 
Table 4. Effect of tribenuron-methyl, foramsulfuron and triflusulfuron-methyl and adjuvant selection on crops tolerance ${ }^{a)}$

\begin{tabular}{|c|c|c|c|c|c|}
\hline Treatments & Wheat response $(\%)^{b)}$ & Treatments & Corn response $(\%)^{b)}$ & Treatments & Sugar beet response $(\%)^{b)}$ \\
\hline Tribenuron-methyl & & Foramsulfuron & & Triflusulfuron-met & \\
\hline (11.3 g a.i./ha) & & (40 g a.i./ha) & & (20 g a.i./ha) & \\
\hline No adjuvant & 2.3 & No adjuvant & 2.0 & No adjuvant & 2.3 \\
\hline Zonyl FSN-100 & 5.3 & Zonyl FSN-100 & 8.7 & Zonyl FSN-100 & 3.0 \\
\hline PF-151N & 5.8 & PF-151N & 4.3 & PF-151N & 4.0 \\
\hline Brij 35 & 8.8 & Brij 35 & 3.3 & Brij 35 & 8.3 \\
\hline $\operatorname{LSD}_{0.05}$ & 0.50 & $\operatorname{LSD}_{0.05}$ & 0.75 & $\operatorname{LSD}_{0.05}$ & 0.48 \\
\hline
\end{tabular}

a) Adjuvant doses were Zonyl FSN-100 at $0.01 \% \mathrm{v} / \mathrm{v}$, Brij 35 0.04\%, and PF-151N 0.1\% v/v. ${ }^{b)}$ Crop response observations were made 14 days after treatment (DAT).

more, local surfactant phytotoxicity on the leaf surface with consequent localized cell death and inability of the herbicide to move out of this zone to the site of action has been well recognized. ${ }^{35,36)}$ In particular, phytotoxicity has been related to surfactant structure and EOs content (low EOs being more phytotoxic than higher EOs). ${ }^{37}$

Spreading effects are shown in Fig. 4, where drops of three different solutions made with water and one of the three surfactants were on a hydrophobic film and a picture was taken after $20 \mathrm{~min}$. The evidence provided by the picture suggests that the coverage achieved by the surfactants could be ranked as PF-151N>Zonyl FSN-100>Brij 35. Although PF-151N provided better spreading, it did not provide the best results in terms of weed-enhancing control; in fact, the interaction be-



Fig. 2. Amount of triflusulfuron-methyl absorbed (alone and with various fluorinated adjuvants) in giant foxtail leaves. Vertical bar is $\operatorname{LSD}(P<0.05)$. tween surfactant, herbicide, and plant surface is far more complex than simply lowering the surface tension of the pesticide solution. Fluorocarbon surfactants concentrate at the liquid air interface, whereas hydrocarbon surfactants tend to concentrate at condensed phase interfaces providing a better "bridge" between water and wax on the leaf surface. Due to the fact that both Zonyl FSN-100 and PF-151N are partially fluorinated surfactants they behave in a way which is in between that of fluorocarbon and hydrocarbon surfactants, but since PF-151N molecules are more branched than Zonyl FSN-100, they possibly remain more at the water air interface than Zonyl FSN-100 molecules.

In conclusion, the application rate of triflusulfuron-methyl could be significantly reduced to nearly $1 / 2$ of the labelled rate to control redroot pigweed, with no loss in weed control efficacy; this reduction was favoured by the use of Zonyl



Fig. 3. Amount of tribenuron-methyl absorbed (alone and with various fluorinated adjuvants) in catchweed leaves. Vertical bar is $\operatorname{LSD}(P<0.05)$. 


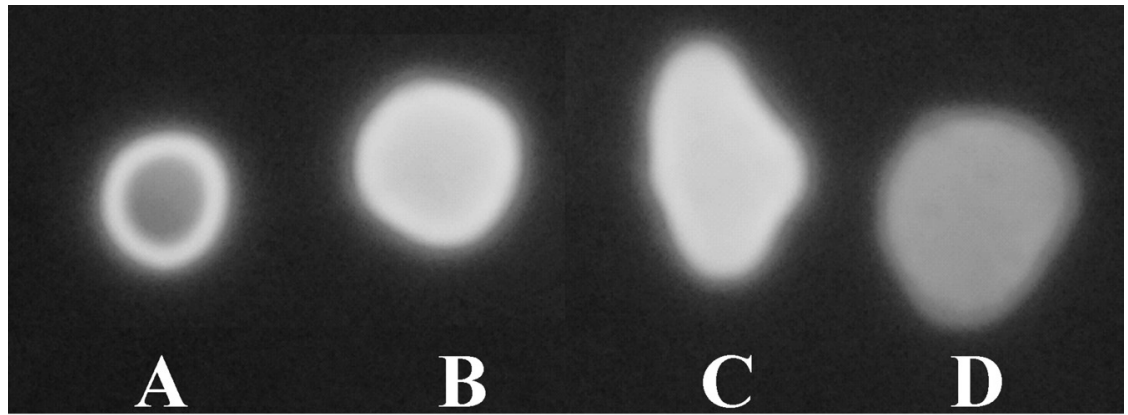

Fig. 4. Spreading of solution drops $(5 \mu 1)$ over a hydrophobic film under UV light, 20 min after deposition. A: Water; B: Brij $35+$ water; C: Zonyl FSN-100+ water; D: PF-151N+water.

FSN-100 and Brij 35. In the case of giant foxtail, the addition of Zonyl FSN-100 and Brij 35 was not enough to allow the control of the weed at the labelled rate.

The foramsulfuron rate was reduced by more than $50 \%$ to control barnyardgrass thanks to the addition of Zonyl FSN100. Foramsulfuron was effective against giant foxtail only when applied at the maximum labelled rate mixed with Zonyl FSN-100. This sulfonylurea did not prove effective against common lambsquarters, regardless of the application rate and adjuvant.

The tribenuron-methyl activity against poppy was only slightly enhanced by the use of adjuvants (Brij 35, Zonyl FSN-100 and PF-151N allowed $20 \%, 14 \%$ and $7 \%$ of dose reduction, respectively), and no significant differences between them were observed. The effect of the adjuvant in improving the herbicide efficacy of tribenuron-methyl for the control of catchweed was apparent, but the dose was not reduced to the labelled rate.

In general, between the two tested fluorinated surfactants, Zonyl FSN-100 seems to be more efficient than PF-151N in enhancing the herbicide efficacy of the tested sulfonylureas. When the fluorinated surfactant Zonyl FSN-100 is compared to the hydrocarbon surfactant Brij 35, in most cases no differences in enhancing herbicide efficacy are found. Nevertheless, the application dose of Zonyl FSN-100 is reduced by four times with respect to the hydrocarbon surfactant.

Although the addition of the tested adjuvants induced low herbicide phytotoxicity in the crops, all injury symptoms had dissipated by 28 DAT.

\section{References}

1) R. G. Hartzler and C. L. Foy: Weed Sci. 31, 557-561 (1983).

2) D. D. Buhler and O. C. Burnside: Weed Sci. 32, 574-583 (1984).

3) M. B.Wixson and D. R. Shaw: Weed Technol. 5, 817-822 (1991).

4) K. N. Harker: Weed Technol. 6, 865-870 (1992).

5) S. E. Hart, J. J. Kells and D. Penner: Weed Technol. 6, 592-598 (1992)

6) P. Kudsk: Brighton Crop Protection Conference-Weeds, 545-554 (1989).
7) D. Penner: Weed Technol. 14, 785-791 (2000).

8) http://www.ext.colostate.e du/pubs/crops/00564.html

9) J. Coret, B. Bambonnet, F. Brabet and A. Chamel: Pestic. Sci. 38, 201-209 (1993).

10) R. C. Kirkwood: Pestic. Sci. 55, 69-77 (1999).

11) H. Tamura, M. Knoche and M. J. Bukovac: J. Agric. Food Chem. 49, 1809-1816 (2001).

12) F. S. Roggenbuck, D. Penner, R. F. Burow and B. Thomas: Pestic. Sci. 37, 121-125 (1993).

13) J. M. Green: "Herbicide Adjuvants," Presented at the UC Davis WRIC Weed Science School, September 26-28, Woodland, 2001.

14) E. M. Beyer, M. J. Duffy, J. V. Hay and D. D. Schlueter: "Herbicides: Chemistry, Degradation, and Mode of Action," Vol. 3, ed. by P. C. Kearney and D. D. Kaufman, Marcel Dekker, New York, pp. 117-189, 1988.

15) P. Kudsk, K. E. Thonkev and J. C. Streibig: Weed Res. 27, 425-429 (1987).

16) F. A. Manthey, J. D. Nalewaja and E. F. Szelezniak: "Adjuvants and Agrochemicals," Vol. 2, ed. by P. N. P. Chow, C. A. Grant, A. M. Hinshalwood and E. Simundsson, CRC Press, Boca Raton, pp. 139-148, 1989.

17) P. Kudsk: "Adjuvants for Agrichemicals," ed. by C. L. Foy, CRC Press, Boca Raton, pp. 441-448, 1992.

18) J. M. Green, P. A. Brown, D. Berengut and M. J. King: "Adjuvants for Agrichemicals," ed. by C. L. Foy, CRC Press, Boca Raton, pp. 525-532, 1992.

19) F. A. Manthey, R. D. Horsley and J. D. Nalewaja: "Pesticide Formulations and Application Systems," ed. by L. E. Bode and D. G. Chasin, ASTM, Philadelphia, pp. 258-270, 1992.

20) J. M. Green and J. H. Green: Weed Technol. 7, 633-640 (1993).

21) J. M. Green: Weed Technol. 16, 79-83 (2001).

22) D. Stock and P. J. Holloway: Pestic. Sci. 38, 165-177 (1993).

23) G. Covarelli and A. Onofri: 16th COLUMA Conference, 1, 461-464 (1995).

24) D. Silcox and P. J. Holloway: "Adjuvants and Agrochemicals," Vol. 2, ed. by P. N. P. Chow, C. A. Grant, A. M. Hinshalwood and E. Simundsson, CRC Press, Boca Raton, pp. 115-128, 1989.

25) M. Riederer and J. Schönherr: Pestic. Sci. 29, 85-94 (1990).

26) P. Mukerjee and K. J. Mysels: ACS Symp., 9, pp. 239-240 (1975). 
27) E. Kissa (ed.): "Fluorinated Surfactants and Repellents," Marcel Dekker, NY, 2001.

28) J-f. Liu, J-b. Chao, G-b. Jiang, Y-q. Cai and J-m. Liu: J. Chrom. A 995, 21-28 (2003).

29) J. C. Streibig, M. Rudemo and J. E. Jensen: "Herbicide Bioassays," ed. by J. C. Streibig and P. Kudsk, CRC Press, Boca Raton, pp. 29-55, 1993.

30) L. G. Copping, H. G. Hewitt and R. R. Rowe: "Weed Control Handbook: Principles," ed. by R. J. Hance and K. Holly, Blackwell Scientific Publication, Oxford, pp. 261-299, 1990.

31) A. Onofri: Rivista Italiana di Agrometeorologia 3, 40-45 (2005) (in Italian).

32) S. S. Seefeldt, J. E. Jensen and E. P. Fuerst: Weed Technol. 9, 218-227 (1995).

33) J. A. Bunting, C. L. Sprague and D. E. Riechers: Crop Protect. 23, 361-366 (2004).

34) R. Zollinger: Journal of ASTM International 2, 8-16 (2005).

35) M. Knoche, G. Noga and F. Lenz: Crop Protect. 11, 51-56 (1992).

36) C. R. Merrit: Ann. Appl. Biol. 101, 517-525 (1982).

37) J. A. Zabkiewicz: Weed Res. 40, 139-149 (2000). 